\title{
Risk factors and clinical manifestations of cerebral venous thrombosis in patients admitted to Zahedan city hospitals during 2011-2017
}

\author{
Hamed Amirifard', Alireza Khosravi², Hoseinali AKbarian ${ }^{3}$ \\ ${ }^{1}$ Assistant Professor, Department of Neurology, Zahedan University of Medical Science, Zahedan, Iran, ${ }^{2}$ Assistant \\ Professor, Clinical Immunology Research Center, Department of Neurology, Zahedan University of Medical Science, \\ Zahedan, Iran, ${ }^{3}$ General Practitioner, Faculty of Medicine, Zahedan University of Medical Science, Zahedan, Iran
}

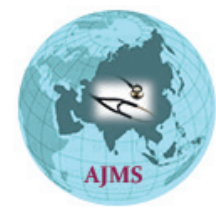

A B S T R A C T

Background: In Cerebral venous thrombosis (CVT), blood clots are create in the veins and, blood clots may form in the veins or sinuses. In $78 \%$ of cases this problem occurred in people lower than 50 years and in women more than men. The annual prevalence of CVT in Iran was 12.3 per one million which was 2.5 times more than world prevalence. Aims and Objective: The aim of this study was to investigate the Risk factors and clinical manifestations of cerebral venous thrombosis in patients admitted to Zahedan city hospitals. Methods and Materials: This retrospective descriptive study was done on 50 patients with CVT which hospitalized in the Zahedan city hospital. Necessary information such as clinical symptoms, risk factors and demographic data extracted from patients file and analyzed by statistical methods in SPSS.16. Results: In this study, $68 \%$ of patients were female and $32 \%$ were male. The most prevalent season was summer age group 34-43 years constituting about $28 \%$ of the cases. The prevalent season was summer with $38 \%$ cases and headache was the most prevalent symptom (66\%). The most prevalent risk factor was infection comprising $30 \%$ of the total patients. Conclusion: Results showed higher prevalence of CVT in women than in men which could be due to the positive relation between prevalence of this disease and risk factors such as oral contraceptive pill (OCP), pregnancy and post-partum period. Also, in this study the most prevalent symptom was headache and the most prevalent season was summer, which could be due to dehydration of patients. The validity of the current study could be further substantiated with study in the similar pattern with more sample size.

Key words: CVT, Risk factor, Clinical symptoms, Zahedan, Iran
http://nepjol.info/index.php/AJMS DOI: 10.3126/ajms.v9i3.19184 E-ISSN: 2091-0576 P-ISSN: $2467-9100$

\section{INTRODUCTION}

Cerebral venous thrombosis (CV'T) is one of the rare stroke types which results in the formation of blood clots in the venous sinuses that responsible for brain drainage. Venous thrombosis can cause Venous infarction that results in brain tissue damage due to congestion and inadequate blood flow. ${ }^{1}$ Although the CVT is rare and includes less than $1 \%$ of strokes but in recent years, its recognition by using MRI and identification its clinical symptoms has increased. ${ }^{2-5}$
CVT was first reported in 1825 and its exact incidence rate is unknown but can affect all age groups from 6 days to 77 years. The average age is 33 years and the prevalence is higher in women. Various factors such as infections, hormonal imbalance, cancers, blood disorders, systemic diseases, trauma, drugs and dehydration ccould be risk factors for CVT.. The clinical symptoms of the disease includes headache, seizure, focal neurological defects and decreased consciousness confirmed by CT scan and MRI. ${ }^{6-15}$ Thrombosis is characterized by two different 
mechanisms, one is a CVT with local effects due to venous obstruction and another one is large sinus thrombosis that leads to an increase intracranial pressure and in most patients, these two processes occur simultaneously. ${ }^{6,7,12,16-21}$ Thrombosis can also be caused by an imbalance between coagulation and fibrinolysis. Three main mechanism of this imbalance included change in normal blood flow, vascular wall damage, changes in hypercoagulable blood composition and in most cases of CVT arises as a result of over coating. ${ }^{1}$

The aim of the current study was to determine the risk factors and clinical manifestations of cerebral venous thrombosis in patients admitted to Zahedan city hospitals during the period of 2011-2017.

\section{MATERIALS AND METHODS}

This is a retrospective descriptive study was done among 50 patients with CVT who were hospitalized in Zahedan city hospitals from April 2011 to April 2017. The method of sampling was census and all of patients entered in the study. Demographic data including age, sex, season of the incidence of CVT, effective risk factors including pregnancy, OCP, infection, blood diseases, idiopathic, using drug or addiction, trauma, history of stroke or CVT, high blood pressure, diabetes mellitus, dehydration, fasting and Blood disorders, clinical symptoms including fever, headache, blurred vision, Lateralized symptoms, seizure and loss of consciousness which was extracted from patient's case history and recorded in a checklist. Due to the inability to examine headache and blurred vision in children under 3 years of age, these two symptoms were studied in patients over 3years old and the use of OCP, pregnancy and postpartum period were studied in women.

\section{Statistical analysis}

Statistical analysis was done using the SPSS 19.0 program (Statistical Package for Social Sciences; SPSS Inc., Chicago, IL, USA) for Windows 8. Frequency and percent were calculated for categorical variables.

\section{RESULTS}

Of all patients included in the study, $68 \%$ were female and rest was male. Of patients less than 3 years old, $81.8 \%$ were male. Most of patients with $28 \%$ were in age group 3443 years (Figure 1) and the most common season was summer comprising of $38 \%$ of the total patients. Headache was presenting symptom in $66 \%$ of patients of the patients which was the most common symptom of the disease (Figure 2). Infection with 30\% was the most common risk factor in this study (Figure 3).

\section{DISCUSSION}

In this study most of patients were in age group 34-43 years (range 6 days to 77 years) and the findings of the present study were consistent with the results of other studies in different regions with a mean age in range of 31-37 years old. ${ }^{22,23}$ In this study $68 \%$ of the patients were women and similar to our study results in most studies, the proportion of women is higher than men. Contraception in women was a major risk factor, so taking contraceptive pills increases the

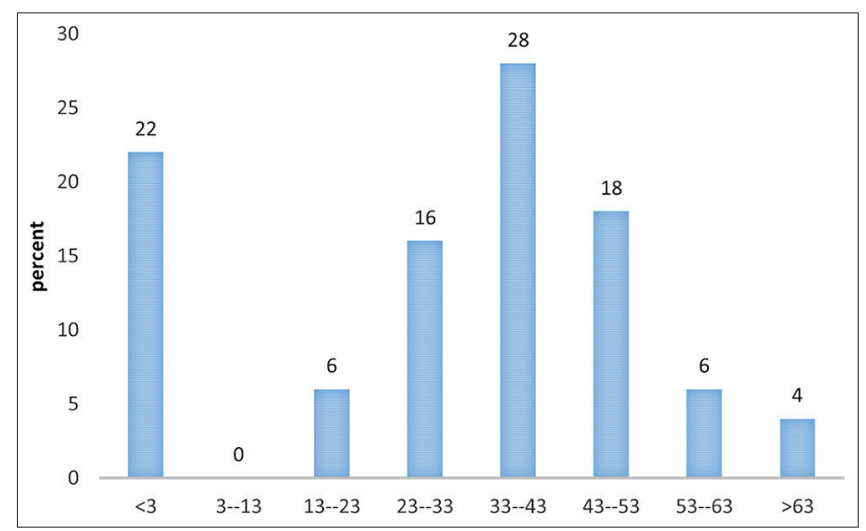

Figure 1: The age distribution of patients

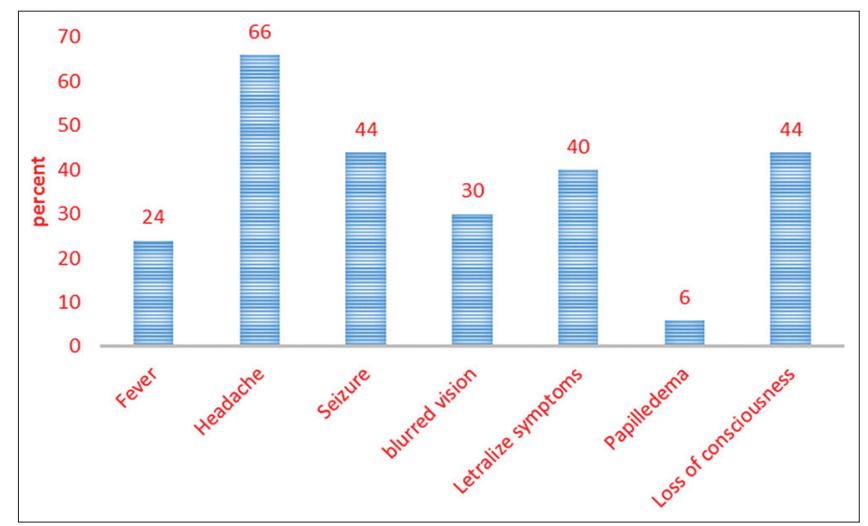

Figure 2: The percent of clinical symptoms in patients

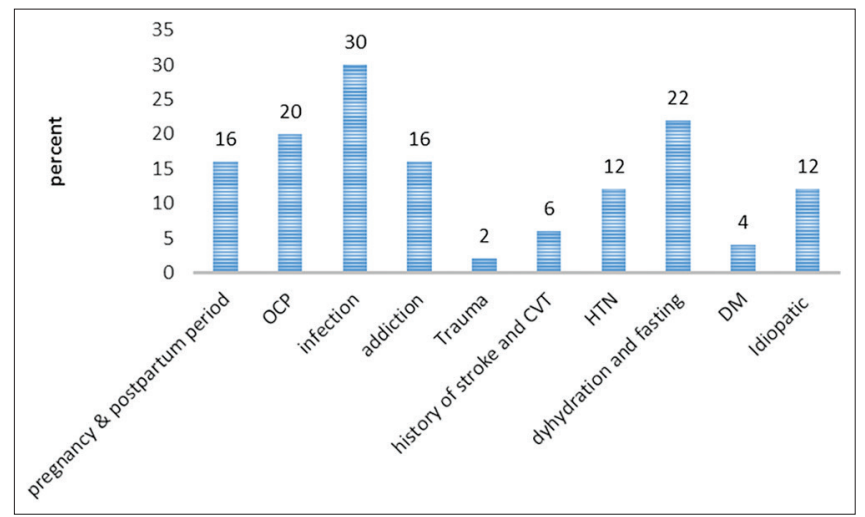

Figure 3: The percent of risk factors in CVT patients 
chances of occurrence thrombosis more than 22 folds. In a study reported elsewhere, $46 \%$ of the patients with sinus thrombosis had history of contraceptive use and $50 \%$ of patients had thrombosis six to eight weeks after delivery. ${ }^{24}$

In the present study, pregnancy and postpartum period, as well as the use of contraceptive pills were the major risk factors but contrary to the present study in other reported studies the male patients exceeded than those of females which could be due to trauma and drug abuse among males. ${ }^{22}$

The prevalence of CVT was more in summer which could be possibly due to dehydration which concurs with the study reported elsewhere ${ }^{9}$ they claimed summer season had the high occurrence along with iron deficiency anemia. Decreased body water in the elderly and headaches were the main risk factors for incidence of thrombosis.?

In the current study, the most common symptom was headache occurred in $66 \%$ of the total of the total patients, followed by seizure, loss of consciousness, Lateralized symptoms and blurred vision. Headache which was due to increased intracranial pressure was observed in $90 \%$ of patients and can be accompanied by other symptoms such as seizure, hemiparesis, and aphasia. ${ }^{25}$

The prevalence of headache were $70 \%, 86.4 \%$ and $100 \%$ in the studies by Foroghipoor et $\mathrm{al}^{22}$ Khomand et $\mathrm{al}^{23}$ and Nikkhah et al ${ }^{26}$ respectively. While in the study of Khomand et $\mathrm{al}^{23}$ Papilledema and blurred vision were the second highest symptom of CVT after headache and in the present study, blurred vision was in the lower rank which was probably due to the lack of examination of patients for Papilledema. In the Foroghipoor study, ${ }^{22}$ headache, Papilledema, motor focal or sensory symptoms and decreased consciousness were the main symptoms that were consistent with the present study. Infection was the most common risk factor for CVT in the current study and other risks were use of OCP, dehydration, fasting, pregnancy and addiction. Foroghipour et $\mathrm{al}^{22}$ stated the most common cause of thrombosis was OCP, pregnancy and infection which was consistent with the findings of the current study. $22,23,26$

In the study of Nikkhah et al ${ }^{26}$ the most common clinical symptom was headache and the causes of thrombosis was use of contraceptives, postpartum period, middle ear infection and nephrotic syndrome which was in concurrence with the present study.

In a review study between 1990 and 2005, the risk factors for thrombosis were genetic prothrombotic conditions, infections, pregnancy and postpartum period, inflammatory diseases, trauma and mechanical causes such as head trauma, dehydration especially in children and hematologic conditions. In another study, $14 \%$ of patients had a history of trauma one month before thrombosis, so head trauma could be a risk factor. ${ }^{27}$

In the present study, infection, pregnancy, postpartum period and dehydration were the major risk factors for CVT with trauma being the lower grade among risk factors. ${ }^{1}$ Another review study from 1987 to 2013 found that CVT is a multi-factorial disease which depends on gender variation and were associated with factors such as brain tumor, head trauma, extra-cerebral neoplasms, dural fistula, hematological conditions, nephrotic syndrome, systemic scoliosis, drugs, neurological surgery, luteal phase (LP), pregnancy, periodontal, OCP use and congenital factors which was almost similar to the findings of the current study. The most common symptom of this study was headache and other symptoms including mild paralysis, Papilledema, change the consciousness condition, aphasia, dizziness, coma, double vision and visual disturbances whereas in the present study, headache was the most common clinical symptom, followed by by loss of consciousness and visual disturbances.. It seems that gender is involved in the development of the disease and so prevention of vascular thrombosis is a vital and effective way to reduce mortality during pregnancy and postpartum period. ${ }^{28,29}$

\section{CONCLUSION}

The results of this study showed that the high prevalence of Venous sinus thrombosis more in women compared to men can be indicative of the association of this disease with risk factors such as the use of OCP,pregnancy and postpartum period. The most common symptom was headache and the summer being the most common month of occurrence which could be due to dehydration in patients.

\section{Limitation of the study}

Considering the low number of patients in this study and the high proportion of males involvement in children and the difference in risk factors and clinical symptoms. We suggest that a study that a study be conducted with longer duration and population and a study in the pediatric age group. Also, by conducting case studies in OCP users with thrombosis of the venous sinuses, we can obtain useful information in this regard.

\section{CONFLICT OF INTEREST}

\section{None declared}

Asian Journal of Medical Sciences | May-Jun 2018 | Vol 9 | Issue 3 


\section{ACKNOWLEDGEMENT}

Authors would like to thanks all of patients participated in the study.

\section{REFERENCES}

1. Stam J. Thrombosis of the cerebral veins and sinuses. New England Journal of Medicine 2005; 352(17):1791-1798.

2. Ferro JM, Lopes GC, Rosas MJ, Bravo Marques JM and Costa JB. Do randomised clinical trials influence practice. Journal of Neurology2002; 249,1595-1596.

3. Ferro JM, Canhão $P$, Bousser $M-G$, Stam $J$ and Barinagarrementeria F. Early Seizures in Cerebral Vein and Dural Sinus Thrombosis. Stroke 2008; 39(4):1152-1158.

4. Lafitte F, Boukobza M, Guichard J, Hoeffel C, Reizine D, Ille O, et al. MRI and MRA fordiagnosis and follow-up of cerebral venous thrombosis (CVT). Clinical Radiology 1997;52(9):672-679.

5. Dormont D, Anxionnat R, Evrard S, Louaille C, Chiras J and Marsault C. MRI in cerebral venous thrombosis. Journal of Neuroradiology 1994;21(2):81-99.

6. Bousser MG and Russell R. Cerebral venous thrombosis. London: WB Saunders. 1997:385-389.

7. Fishman R. Cerebral veins and sinuses. Rowland LP Merriit Neurology $11^{\text {th }}$ ed Philadelphia: Lippincott Willlams \& Wilkins. 2005:338-41.

8. Dentali F, Gianni M, Crowther MA and Ageno W. Natural history of cerebral vein thrombosis: a systematic review. Blood 2006; 108(4):1129-1134.

9. Zétola VHF, Nóvak EM, Camargo CHF, Carraro Júnior $\mathrm{H}$, Coral $\mathrm{P}$ Muzzio JA, et al. Stroke in young adults: analysis of 164patients. Arquivos de neuro-psiquiatria 2001; 59(3B):740-745.

10. Black C, Kaye JA and Jick H. Clinical risk factors for venous thromboembolus in users of the combined oral contraceptive pill. British Journal of Clinical Pharmacology 2002;53(6):637-640.

11. Aaron S, Alexander M, Maya T, Mathew V, Goel M, Nair S, et al.Underlying prothrombotic states in pregnancy associated cerebral venous thrombosis. Neurology India 2010; 58(4):555.

12. Ferro JM, Canhão $P$, Stam J, Bousser $M G$ and Barinagarrementeria F. Prognosisof cerebral vein and dural sinus thrombosis. Stroke 2004; 35(3):664-670.

13. Majoie $\mathrm{CB}$, van Straten M, Venema HW and den Heeten GJ. Multisection CT venography of the dural sinuses and cerebral veins by using matched mask bone elimination. American Journal of Neuroradiology 2004;25(5):787-791.

14. Isensee $\mathrm{C}$, Reul $\mathrm{J}$ and Thron A. Magnetic resonance imaging of thrombosed dural sinuses. Stroke 1994; 25(1):29-34.

15. Ayanzen R, Bird C, Keller P, McCully F, Theobald M and
Heiserman J. Cerebral MR venography: normal anatomy and potential diagnostic pitfalls. American Journal of Neuroradiology 2000;21(1):74-78.

16. Biller $\mathrm{J}$ and Love BB. Vascular diseases of the nervous system. Neurology in Clinical Practice The Neurological Disorders $4^{\text {th }}$ ed Philadelphia: Butterworth Heınemann 2004; 251, 1197.

17. Ropper AH. Adams and Victor's principles of neurology: McGraw-Hill Medical Pub. Division New York; 2005.

18. Corvol J, Oppenheim C, Manai R, Logak M, Dormont D, Samson $Y$, et al. Diffusion-weighted magnetic resonance imaging in a caseof cerebral venous thrombosis. Stroke 1998;29(12):2649-2652.

19. Yoshikawa T, Abe O, Tsuchiya K, Okubo T, Tobe K, Masumoto T, et al. Diffusion-weighted magnetic resonance imaging of dural sinus thrombosis. Neuroradiology 2002; 44(6),481-488.

20. De Bruijn S, Stam J, Kappelle L and Group CS. Thunderclap headache as first symptom of cerebral venous sinus thrombosis. The Lancet 1996; 348(9042):1623-1625.

21. Kothare SV, Ebb DH, Rosenberger PB, Buonanno F, Schaefer PW and Krishnamoorthy KS. Acute confusion and mutism asa presentation of thalamic strokes secondary to deep cerebral venous thrombosis. Journal of Child Neurology 1998; 13(6):300-303.

22. Foroughipoor M, Moghaddam Ahmadi A, Fadaei S, Ravankhah Moghaddam K and SharifiRazavi A. Causes of Cerebral Venous Thrombosis and its Clinical Manifestation in Patients Admitted in Emergency Unit and Neurology Ward of Ghaem Hospital. J Mazandaran Univ Med Sci 2013; 23 (98):86-90.

23. Khomand $P$, Ahsan B, Gharibi F and KhadamiAH. An evaluation of the frequency of cerebral venous sinus thrombosis and its associated factors in Sanandaj, 2010-2011, Iran. Qom University of Medical Sciences Journal 2014;8(3):49-54.

24. McPhedran P (2004). Venous thromboembolism during pregnancy. Medical Complications During Pregnancy $6^{\text {th }}$ ed Philadelphia, PA: Elsevier Saunders,95,7.

25. Buccino G, Scoditti U, Patteri I, Bertolino C and Mancia D. Neurological and cognitive long-term outcome in patients with cerebral venous sinus thrombosis. Acta Neurologica Scandinavica 2003; 107(5):330-335.

26. Nikkhah K,Sasannejad P,Azarpazhoh M,Saidi M and Afshar L. Brain Venous Thrombosis. MUMS 2009; 52(3):147-150.

27. Delgado Almandoz JE, Kelly HR, Schaefer PW, Lev MH, Gonzalez RG and Romero JM. Prevalence of traumatic dural venous sinus thrombosis in high-risk acute blunt head trauma patients evaluated with multidetector CT venography. Radiology 2010; 255(2):570-577.

28. Alvis-Miranda HR, Castellar-Leones SM, Alcala-Cerra G and Moscote-Salazar LR. Cerebral sinus venous thrombosis. Journal of Neurosciences in Rural Practice 2013; 4(4):427.

29. Keypour F and Naghi I. Sagittal venous sinus thrombosis after cesarean section: a case report. Tehran University Medical Journal TUMS Publications 2013; 71(4): 265-269.

\footnotetext{
Authors Contribution:

HA- Concept and design of the study, reviewed the literature, manuscript preparation and critical revision of the manuscript; AK- Concept, collected data and review of literature, statistically analyzed and interpreted, helped in preparing first draft of Manuscript; HA- Conceptualized study, literature search, prepared first draft of manuscript and critical revision of the manuscript.

Work attributed to:

Dr. B. R. Ambedkar Center for Biomedical Research, University of Delhi, Delhi, India.

Orcid ID:

Dr.Alireza Khosravi- (i) http://orcid.org/0000-0002-9182-1220

Dr.Hamed Amirifard- (1) http://orcid.org/0000-0001-7675-5328

Source of Support: Zahedan University of Medical Science, Conflict of Interest: None declared.
} 